(2) OPEN ACCESS

\begin{abstract}
- Additional material is published online only. To view please visit the journal online (http://dx.doi.org/10.1136/ oemed-2020-106554).
\end{abstract}

${ }^{1}$ Analysis and Data, National Research Centre for the Working Environment, Copenhagen, Denmark

${ }^{2}$ Health Sciences, Community and Occupational Medicine, University of Groningen, Groningen, Netherlands ${ }^{3}$ Musculoskeletal disorders and physical workloads, National Research Centre for the Working Environment, Copenhagen,

Denmark

${ }^{4}$ QualityMetric, Johnston, Rhode Island, USA

${ }^{5}$ Department of Public Health, University of Copenhagen, Copenhagen, Denmark

Correspondence to Dr Sannie Vester Thorsen, Analysis and Data, The National Research Centre of the Working Environment, Copenhagen DK2100, Denmark; svt@nrcwe.dk

Received 18 March 2020 Revised 16 July 2020 Accepted 25 July 2020 Published Online First 9 September 2020

\title{
Associations between physical and psychosocial work environment factors and sickness absence incidence depend on the lengths of the sickness absence episodes: a prospective study of 27678 Danish employees
}

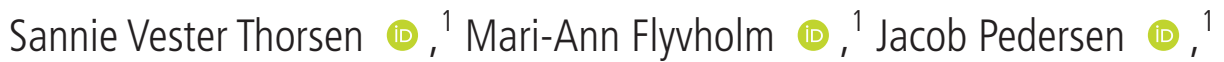 \\ Ute Bültmann (10 , 1,2 Lars L Andersen (10) ${ }^{3}$ Jakob Bue Bjorner (1) 1,4,5
}

\section{ABSTRACT}

Objectives This study examined if the association between work environment factors and sickness absence (SA) depended on the inclusion or exclusion of shortterm SA episodes.

Methods We linked the 'Work Environment and Health in Denmark' survey with the 'Danish Register of Work Absences' ( $n=27678$ ). Using covariate adjusted Cox regression, we examined the associations between work environment factors and SA by changing the cut-off points for the length of the SA episodes, for example, episodes $\geq 1$ day, $\geq 6$ days and $\geq 21$ days. We examined three physical work environment factors: 'Back bend or twisted', 'Lifting or carrying', 'Wet hands' and three psychosocial work environment factors: 'Poor influence', 'Role conflicts' and 'Bullying'.

Results 'Back bend or twisted' and 'Lifting or carrying' had small significant HRs for SA episodes $\geq 1$ day and large and highly significant HRs for SA episodes $\geq 6$ days and $\geq 21$ days. 'Wet hands' had small significant HRs for SA episodes $\geq 1$ day for both sexes and large and highly significant $H R$ for $\geq 6$ days for women. HRs of all three psychosocial factors were highly significant for SA episodes $\geq 1$ day and $\geq 6$ days for both sexes, and 'Poor influence' and 'Role conflicts' were significant for SA episodes $\geq 21$ days for women.

Conclusions The physical work factors had higher associations with SA when SA episodes of 1-5 days were excluded and focus was on SA episodes $\geq 6$ days. The psychosocial work factors were strongly associated with SA both with and without SA episodes of $1-5$ days included in the analyses.

\section{BACKGROUND}

In Denmark, 3.6\% of all work hours are lost due to sickness absence (SA). ${ }^{1}$ The expense of SA benefits alone exceeds 1.3 billion euro per year ${ }^{2}$ not counting the additional cost of lost productivity and healthcare expenses. Knowledge about the association between work environment factors and SA is a prerequisite for reducing SA through preventive efforts.

Poor work environment is associated with longterm SA. ${ }^{3}$ Psychosocial work environment factors

\section{Key messages}

What is already known about this subject?

- Poor physical and poor psychosocial work environment factors are associated with longterm sickness absence from work.

- Short-term sickness absence (1-5 days) constitutes a considerable part of the total sickness absence from work.

What are the new findings?

- Physical work environment factors 'Back bend or twisted' and 'Carrying and lifting' were strongly associated with sickness absence of $\geq 6$ days for both men and women, but the inclusion of short-term sickness absence episodes (1-5 days) deflated the association.

- The psychosocial work environment factors 'Role conflict' and 'Bullying' were strongly associated with sickness absence of $\geq 6$ days for both men and women. Including short-term sickness absence episodes of 1-5 days only slightly deflated the association.

How might this impact on policy or clinical practice in the foreseeable future?

- Work environment interventions that reduce strenuous physical work may reduce sickness absence episodes of $\geq 6$ days. Work environment interventions that improve different aspects of the psychosocial work environment may be important in the prevention of sickness absence of all lengths.

such as low influence, ${ }^{45}$ low decision authority, ${ }^{67}$ role conflicts ${ }^{35}$ and exposure to bullying ${ }^{9}$ have been associated with long-term SA in several studies. Physical work environment factors such as excessive ergonomic exposures (bending and twisting of neck or back, lifting and carrying, squatting and kneeling, etc) and heavy physical workload have consistently been associated with long-term SA among men and women. ${ }^{10-12}$ Exposure of the hands to wet work has been associated with longterm SA in women. ${ }^{13}$ 
However, there is no consensus regarding the definition of long-term SA. Earlier, long-term SA has been defined as episodes exceeding 7 days, ${ }^{14} 14$ days, ${ }^{15} 20$ days $^{4}, 30$ days $^{16}$ or even 56 days $^{3}$. In Denmark, it is estimated that episodes of 1-7 days account for $44 \%$ of all SA days. ${ }^{1}$ While this percentage may be high, compared with other Nordic countries, ${ }^{17} 18$ studies that exclude short-term SA from analyses ignore a large part of the total SA. If short-term SA is unrelated to the work environment, it would make sense to exclude it, since it would only add noise to a study. Most studies have excluded short-term SA, perhaps because data of short-term SA were lacking or perhaps because short-term SA episodes were considered to be caused by diseases that are not or to a lesser extent influenced by the work environment, for example, a influenza or a cold. However, given data on all SA are available, the question arises: should short-term SA be excluded? And if it should, how much of the short-term SA should be excluded? Episodes of 1 day? Episodes less than 7 days? Episodes less than 21 days?

Theoretically, several mechanisms may explain the associations between work environment factors and SA. Work may cause disease or worsen an existing disease. The disease may cause the employee to call in sick because of reduced work ability, required time for treatment or (for infectious diseases) the risk for coworkers or clients/customers. Moreover, for a given level of work ability, the work environment may affect the individual's decision to go to work or to call in sick. SA is a nonspecific outcome, potentially influenced by many factors.

Using the Danish Register of Work Absences (RoWA), ${ }^{19}$ which include SA of all lengths, the present study systematically examined the associations between work environment factors and SA where SA was defined respectively as SA episodes $\geq 1, \geq 2, \geq 4$, $\geq 6, \geq 8, \geq 12, \geq 16, \geq 21$ and $\geq 31$ days. If short-term SA episodes are primarily related to infectious diseases and not influenced by the work environment, we expect inclusion of short-term episodes to add noise to the analyses and deflate the associations between work environment factors and SA. However, if shortterm SA episodes are influenced by work environment factors, we expect strong associations between these work environment factors and SA when short-term SA episodes are included in the analyses.

The present study aims to answer two questions: (1) Do the associations between physical and psychosocial work environment factors and incidence of SA depend on the inclusion/exclusion of short-term SA? and (2) What is the optimal threshold for length of SA to be included in analyses for the highest associations? We examined the associations between work environment factors and SA for both men and women.

\section{METHODS}

\section{Study design}

We linked work environment data from the Work Environment and Health in Denmark (WEHD) survey ${ }^{20}$ with SA data from the Danish RoWA. ${ }^{21}$ We followed the respondents for up to 18 months in RoWA.

\section{WEHD survey}

The Danish National Research Centre for the Working Environment conducted the WEHD survey biannually from 2012 to 2016 as part of an occupational health and safety surveillance. Eligible employees had to fulfil the following criteria: age 18-64 years, monthly income minimum Kr3000/€400 (average last 3 months), and minimum 8 weekly work hours (average last 3 months). Each survey year, eligible employees were drawn from the Danish population using a stratified probability sample. The employees received a letter with an invitation to participate in a web-based survey. Non-respondents received a reminder by phone and later a reminder by letter with a paper-questionnaire.

\section{Danish Register of Work Absences}

Statistic Denmark have since 2007 registered SA data, irrespectively of episode length, in RoWA. RoWA is a combination of Statistics Denmark's 'Absence and Employment'-register (FRAN) and 'Periods of Absence'-register (FRPE). The RoWA contains start and end dates of the absence periods due to 'own sickness', 'child sickness', 'occupational injury' and 'maternity and adoption leave' from (1) all public institutions, (2) all private companies with more than 250 employees, and (3) a probability sample of private companies with 10-250 employees (a new sample drawn every year). Private companies with less than 10 employees are not included in RoWA. ${ }^{21}$

\section{Study population}

A total of 104329 employees were invited to participate in the WEHD survey (a new sample each survey round, 2012: $\mathrm{n}=35$ 034, 2014: $\mathrm{n}=34736,2016: \mathrm{n}=34559)$, of which 51552 (49\%) responded to the questionnaire (respondents 2012: $n=17$ 662 (50\%), 2014: $n=17486$ (50\%), 2016: $n=16404(47 \%))$. As RoWA covers $100 \%$ of all public employees and about $37 \%$ of all private employees, 32191 WEHD respondents could be linked to the RoWA. We excluded 2525 (8\%) employees that had received SA benefit (due to long-term SA ( $\geq 31$ days)) in 2 years preceding response date, and 1988 (7\%) employees, with missing answers to main questions and main covariates, leaving $\mathrm{n}=27678$ employees (women $\mathrm{n}=16356$, men $\mathrm{n}=11322$ ). Of these, $n=22919$ employees (women $n=13577$, men $n=9342$ ) had complete questionnaire data on the secondary covariates chronic illness, smoking and exercise.

\section{Physical and psychosocial work environment factors}

This study used three physical and three psychosocial work environment factors from the WEHD survey: (1) 'Back twisted or bend', (2) 'Lifting or carrying burdens', (3) 'Wet hands', (4) 'Influence', (5) 'Role conflicts', and (6) 'Bullying'. All factors were measured with one question, except 'Influence' that was measured as the average of two questions. The questions, response categories, scoring and the answers' distribution are in online supplementary material. The questions have shown predictive validity in previous research, that is, 'Back twisted or bend', 'Lifting or carrying burdens', 'Role conflicts' ('Role conflicts' is formulated slightly different) have predicted longterm SA, 'Wet hands' has predicted hand eczema ${ }^{22}$ and bullying has predicted onset of depression. ${ }^{23}$ We scored 'Back bend or twisted', 'Lifting or carrying', 'Wet hands' and 'Bullying' as yes/ no variables, and 'Influence' and 'Role conflicts' with increasing values for each response-category, following scoring-methods from previous research. ${ }^{102425}$

\section{SA outcome}

Outcome was 'own sickness' (all-cause SA) from RoWA. In different analyses, we used SA episodes of $\geq 1, \geq 2, \geq 4, \geq 6, \geq 8$, $\geq 11, \geq 16, \geq 21, \geq 26$, and $\geq 31$ days.

\section{Covariates}

We used the following covariates: age (in years), education $(0=$ primary school or no record $(n=137)$ of education, $1=$ upper secondary school, $2=$ apprentice/trainee, $3=$ short 
higher education, $4=$ long higher education), sector (private or public, of which public is further divided into state, region and municipality), survey rounds (2012, 2014 and 2016), previous SA (any SA in the last 2 months up to baseline (yes/no)), smoking $(0=$ never, 1 =quit smoking, $2=$ smoke sometimes, $3=$ smoke daily), exercise $(1=$ no exercise or at most 2 hours of light exercise per week, $2=$ more than 2 hours light exercise or/and at most 4 hours of medium exercise per week, $3=$ more than 4 hours a week of medium exercise or/and at most 2 hours hard exercise per week, $4=$ more than 2 hours per week of hard exercise), and receiving treatment in the last 12 months for chronic illnesses: depression (yes/no), back disease (yes/no), eczema (yes/no), other long standing illness (yes/no).

Sector and survey round were categorical variables; all other covariates were continuous variables. Sex, age, sector and previous SA were derived from RoWA, education from Statistics Denmark's 'education program' register (UDDF, the register has information about highest completed education); all other variables were from the WEHD questionnaires.

\section{Statistical analysis}

We used a Cox-regression model with recurrent events. Christensen et $a l^{26}$ recommended the Cox model with recurrent events over Poisson regression for SA analyses, because Poisson regression had, for example, less statistical power. We used the statistical program SAS V.9.4 and the procedure Phreg.

Cox regression uses 'time to event', and 'event (yes/no)' in the analyses. We followed employees from the day they answered the questionnaire up until a SA-event happened. The Cox regression with recurrent events allows an employee, who has returned to work after a SA-event, to re-enter the model with a new entry date, 'time to event' and 'event (yes/no)'. To adjust for an employee may enter the model several times, the model uses the 'robust sandwich estimator' that takes into account the within subject correlation. ${ }^{27}$ This adjustment will result in wider CI than if all 'time to event' and 'event (yes/no)' data had been from independent employees. We censored employees during periods of maternity leave or absences due to occupational injury. Employees were also censored, if they lost their job or if their workplace no longer were included in the register $(n=4884)$. Average follow-up time was 14 months. The proportional hazard assumption of the Cox regression model was tested by visual inspection of cumulative hazard plots and Schoenfeld residuals. ${ }^{27} 28$

All analyses were stratified for sex and adjusted in two steps. In model 1, we adjusted for the following covariates: age, education, sector and survey rounds. In model 2, we additionally adjusted for: previous SA, smoking, exercise, chronic illnesses, and we adjusted physical work environment factors for psychosocial work environment, and psychosocial work environment factors for physical work environment. To avoid multicollinearity from closely related variables, we did not mutually adjust the three psychosocial work environment factors or mutually adjust the three physical work environment factors. ${ }^{29}$

To test if HRs were significantly different for men and women, we included an interaction term between sex and the particular work environment factor in analysis including data from both sexes. If the interaction term was significant, the HRs were significantly different.

We performed separate analyses with the above models where we systematically changed the definition of an SA event, including SA episodes of $\geq 1, \geq 2, \geq 4, \geq 6, \geq 8, \geq 11, \geq 16, \geq 21, \geq 26$ and
Table 1 Sample characteristics of $n=27678$ Danish employees in the study

\begin{tabular}{|c|c|c|c|c|c|c|}
\hline & \multirow{2}{*}{$\frac{\text { Women }}{\mathrm{N}}$} & \multirow{2}{*}{ Per cent } & \multirow[b]{2}{*}{ Mean } & \multirow{2}{*}{$\begin{array}{l}\text { Men } \\
\mathrm{N}\end{array}$} & \multirow[b]{2}{*}{ Per cent } & \multirow[b]{2}{*}{ Mean } \\
\hline & & & & & & \\
\hline Age (years) & 16356 & & 46.4 & 11322 & & 46.9 \\
\hline $\begin{array}{l}\text { Follow-up time } \\
\text { (months) }\end{array}$ & 16356 & & 14.2 & 11322 & & 13.7 \\
\hline \multicolumn{7}{|l|}{ Sector } \\
\hline Private sector & 4752 & 29.1 & & 6982 & 61.7 & \\
\hline Public sector & 11604 & 70.9 & & 4340 & 38.4 & \\
\hline \multicolumn{7}{|l|}{ Education } \\
\hline Primary school & 1588 & 9.7 & & 1477 & 13.0 & \\
\hline $\begin{array}{l}\text { Upper } \\
\text { secondary } \\
\text { school }\end{array}$ & 1088 & 6.7 & & 798 & 7.0 & \\
\hline $\begin{array}{l}\text { Apprentice/ } \\
\text { trainee }\end{array}$ & 4858 & 29.7 & & 3804 & 33.6 & \\
\hline $\begin{array}{l}\text { Short higher } \\
\text { education }\end{array}$ & 6500 & 39.7 & & 3135 & 27.7 & \\
\hline $\begin{array}{l}\text { Long higher } \\
\text { education }\end{array}$ & 2322 & 14.2 & & 2108 & 18.6 & \\
\hline \multicolumn{7}{|l|}{ Chronic illnesses } \\
\hline Depression & 771 & 4.8 & & 361 & 3.2 & \\
\hline Back disease & 1423 & 8.9 & & 1024 & 9.2 & \\
\hline Eczema & 1489 & 9.3 & & 821 & 7.4 & \\
\hline Other illness & 3563 & 22.3 & & 1923 & 17.3 & \\
\hline \multicolumn{7}{|l|}{ Smoking } \\
\hline Never & 8527 & 52.4 & & 5763 & 51.2 & \\
\hline Quit & 4725 & 29.1 & & 3237 & 28.7 & \\
\hline Sometimes & 849 & 5.2 & & 643 & 5.7 & \\
\hline Daily & 2159 & 13.3 & & 1618 & 14.4 & \\
\hline \multicolumn{7}{|l|}{ Exercise } \\
\hline Light exercise & 1021 & 7.4 & & 703 & 7.4 & \\
\hline $\begin{array}{l}\text { Light-medium } \\
\text { exercise }\end{array}$ & 5141 & 37 & & 2489 & 26.2 & \\
\hline $\begin{array}{l}\text { Medium-hard } \\
\text { exercise }\end{array}$ & 7270 & 52.4 & & 5582 & 58.7 & \\
\hline Hard exercise & 447 & 3.2 & & 742 & 7.8 & \\
\hline \multicolumn{7}{|l|}{$\begin{array}{l}\text { Employees with } \\
\text { recurrent SA } \\
\text { episodes }\end{array}$} \\
\hline No episodes & 3810 & 23.3 & & 4438 & 39.2 & \\
\hline 1 episode & 2984 & 18.3 & & 2347 & 20.7 & \\
\hline $\begin{array}{l}2 \text { or more } \\
\text { episodes }\end{array}$ & 9562 & 58.5 & & 4537 & 40.1 & \\
\hline
\end{tabular}

SA, sickness absence.

$\geq 31$ days, respectively, to examine if the HRs depended on the cut-off point for inclusion/exclusion of short-term SA.

\section{RESULTS}

Our final sample included a wide variety of Danish employees (see table 1), for example, both private and public sector, and both employees with short and long education. Women had 48261 SA episodes and men had 21150 SA episodes (table 2). A small subset of these (6038 episodes for women and 2293 episodes for men) lasted 6 days or longer, and only 2055 episodes for women and 622 episodes for men lasted 21 days or longer. Thus, short-term SA episodes were more frequent than long-term SA episodes. 
Table 2 Number of sickness absence (SA) episodes for different cutoff points for the length of the SA episodes

\begin{tabular}{lllll}
\hline & Women & Per cent & Men & Per cent \\
\hline SA episodes $\geq 1$ day & 48261 & 100 & 21150 & 100 \\
SA episodes $\geq 2$ days & 27447 & 56.9 & 12052 & 57 \\
SA episodes $\geq 4$ days & 10692 & 22.2 & 4541 & 21.5 \\
SA episodes $\geq 6$ days & 6038 & 12.5 & 2293 & 10.8 \\
SA episodes $\geq 8$ days & 4501 & 9.3 & 1677 & 7.9 \\
SA episodes $\geq 12$ days & 3125 & 6.5 & 1086 & 5.1 \\
SA episodes $\geq 16$ days & 2489 & 5.2 & 806 & 3.8 \\
SA episodes $\geq 21$ days & 2055 & 4.3 & 622 & 2.9 \\
SA episodes $\geq 26$ days & 1731 & 3.6 & 518 & 2.4 \\
SA episodes $\geq 31$ days & 1465 & 3.0 & 434 & 2.1 \\
\hline
\end{tabular}

\section{Associations between work environment factors and SA episodes $\geq 1$ day, episodes $\geq 6$ days and episodes $\geq 21$ days}

HRs represent the increased risk for an SA episode at any given time, for example, an HR at 1.30 represents a $30 \%$ increased risk. Table 3 shows the HRs for SA episodes $\geq 1$ day (lowest possible cut-off point), $\geq 6$ days (cut-off point representing the strongest association for many predictors) and $\geq 21$ days (highest cut-off point for which HR could be estimated for most scales). All CIs were smaller for analyses with SA episodes $\geq 1$ day compared with analyses with SA episodes $\geq 6$ days that again were smaller compared with analyses with SA episodes $\geq 21$ days; hence, results were more precise the more SA episodes that were included in the analyses. Figures 1 and 2 show HRs for all cut-off points for the fully adjusted models. The proportional hazards assumption was fulfilled for all analyses with SA episodes $\geq 1$ day and $\geq 6$ days, but it could not be shown to be fulfilled for 'Bullying' at $\geq 21$ days. Tables and figures only show analyses that fulfilled the proportional hazard assumption.

\section{Physical work environment factors}

In the fully adjusted model, 'Back bend or twisted', 'Lifting or carrying' and 'Wet hands' had small associations with SA episodes $\geq 1$ day and large associations with SA episodes $\geq 6$ days (see table 3); for example, for 'Back bend and twisted' for women, the HR at $\geq 1$ day was 1.02 (1.00 to 1.04) and the HR at $\geq 6$ days was 1.24 (1.17 to 1.32 ). The HRs at $\geq 6$ days were considerably higher than the HRs at $\geq 1$ day, that is, most 95\% CIs did not overlap. For SA episodes of $\geq 21$ days, the HRs of 'Back bend or twisted' and 'Lifting or carrying' were significant, HRs of 'Wet hands' were not significant.

The HRs of the physical work environment factors were higher for men than for women in most analyses. The HRs were significantly higher for 'Back bend or twisted' for SA episodes $\geq 1$ day, 'Wet hands' for SA episodes $\geq 1$ day, 'Lifting and carrying' for SA episodes $\geq 6$ days and 'Lifting and carrying' for SA episodes $\geq 21$ days. The $p$ values for interaction were, respectively, $\mathrm{p}=0.003, \mathrm{p}=0.024, \mathrm{p}=0.001, \mathrm{p}=0.011$ (not shown in tables).

\section{Psychosocial work environment factors}

For women, the psychosocial work environment factors 'Poor influence', 'Role conflicts' and 'Bullying' were significantly associated with SA episodes $\geq 1$ day, $\geq 6$ days and $\geq 21$ days in the fully adjusted model, for example, for 'Poor influence' the HRs were, respectively, 1.48 (1.41 to 1.57$), 1.41$ (1.21 to 1.63$)$ and 1.49 (1.15 to 1.92$)$. For 'Role conflicts' and
'Bullying', the HRs were considerably higher for $\geq 6$ days than for $\geq 1$ day, with almost no overlap of the CIs.

For men, the psychosocial work environment factors were significantly associated with $\mathrm{SA}$ episodes $\geq 1$ day and $\geq 6$ days, but not with $\geq 21$ days in the fully adjusted model, for example, for 'Poor influence' the HRs were, respectively, 1.72 (1.59 to 1.85 ), 1.92 (1.53 to 2.42) and 1.32 (0.84 to 2.08). The HRs of the psychosocial work factors were higher for SA episodes $\geq 6$ days than for $\geq 1$ day; however, the CIs had large overlaps.

Men had significantly higher HRs for 'Poor influence' for $\geq 1$ day and $\geq 6$ days compared with women, that is, $p$ values for interaction were $<0.0001$ and 0.013 (not shown in tables). All other HRs were higher, but not significantly higher, for women compared with men.

\section{Sensitivity analyses}

We performed sensitivity analyses, where (1) we weighted data with provided weights for representative population and (2) we split data up in public and private sector. The main result, that is, the HRs of the physical work environment were higher for SA episodes $\geq 6$ days than $\geq 1$ day, were repeated in all sensitivity analyses. See online supplementary material for details.

\section{DISCUSSION}

Our aims were to examine if the associations between physical and psychosocial work environment factors and SA depended on the inclusion/exclusion on short-term SA episodes, and to find the optimal cut-off point for which SA episodes to include/exclude in the analyses.

The physical work environment factors' association with SA was considerably higher if we focused on SA episodes $\geq 6$ days compared with analyses with SA episodes $\geq 1$ day. For 'Back bend or twisted' and 'Lifting or carrying', the magnitude of the associations was stable when we restricted analyses to even longer SA lengths (eg, $\geq 21$ days), but the CIs became larger, that is, the precision of the estimates decreased. The association of 'Wet hands' with SA episode $\geq 21$ days were nonsignificant for both men and women.

The psychosocial work environment factors, 'Role conflict' and 'Bullying' had higher associations with SA if we focused on SA episodes $\geq 6$ days, but associations were also highly significant when 1-5 days SA episodes were included in the analyses, that is, analyses of SA episodes $\geq 1$ day. The associations between 'Poor Influence' and SA were equally strong for SA episodes $\geq 1$ day and $\geq 6$ days.

Men had in general higher associations between physical work environment factors and SA than women. Women had in general higher associations between psychosocial work environment factors and SA than men, except 'Poor influence' where the associations with SA episodes $\geq 1$ day and $\geq 6$ days were significantly higher for men.

The deflation of the association between physical work environment factors and SA, when short-term SA episodes of 1-5 days were included in the analyses, could be explained if short-term SA is primarily associated with other factors. That is, if short-term SA is influenced by factors unrelated to the physical work environment, for example, a cold or a influenza. It is possible that poor physical work environment factors are mainly associated with severe illnesses, for example, chronic pain, ${ }^{30}$ from which it is difficult to recover from in a few days, and therefore, the associations of physical work factors and 
Table 3 HRs for physical and psychosocial work environment factors' association with sickness absence (SA) episodes $\geq 1$ day, $\geq 6$ days and episodes $\geq 21$ days

\begin{tabular}{|c|c|c|c|c|c|c|c|c|c|}
\hline \multirow[b]{2}{*}{ Work environment } & \multicolumn{3}{|c|}{ SA episodes $\geq 1$ day } & \multicolumn{3}{|c|}{ SA episodes $\geq 6$ days } & \multicolumn{3}{|c|}{ SA episodes $\geq 21$ days } \\
\hline & HR & $\mathrm{Cl}$ & $P$ value & $\mathrm{HR}$ & $\mathrm{Cl}$ & $P$ value & HR & $\mathrm{Cl}$ & $P$ value \\
\hline \multicolumn{10}{|c|}{ Physical work environment } \\
\hline \multicolumn{10}{|c|}{ Model 1 partly adjusted ${ }^{*}$} \\
\hline \multicolumn{10}{|l|}{ Women $n=16356$} \\
\hline Back bend or twisted & 1.11 & (1.08 to 1.13$)$ & $<0.0001$ & 1.4 & (1.33 to 1.48$)$ & $<0.0001$ & 1.31 & (1.19 to 1.45$)$ & $<0.0001$ \\
\hline Lifting or carrying & 1.07 & (1.05 to 1.09 ) & $<0.0001$ & 1.31 & (1.24 to 1.39$)$ & $<0.0001$ & 1.37 & (1.24 to 1.51$)$ & $<0.0001$ \\
\hline Wet hands & 1.08 & (1.06 to 1.10$)$ & $<0.0001$ & 1.38 & (1.31 to 1.47 ) & $<0.0001$ & 1.23 & (1.11 to 1.36$)$ & $<0.0001$ \\
\hline \multicolumn{10}{|l|}{ Men $n=11322$} \\
\hline Back bend or twisted & 1.22 & (1.18 to 1.27$)$ & $<0.0001$ & 1.67 & (1.52 to 1.83 ) & $<0.0001$ & 1.73 & (1.45 to 2.07 ) & $<0.0001$ \\
\hline Lifting or carrying & 1.18 & (1.14 to 1.22$)$ & $<0.0001$ & 1.67 & (1.52 to 1.83$)$ & $<0.0001$ & 1.75 & (1.47 to 2.09 ) & $<0.0001$ \\
\hline Wet hands & 1.22 & (1.17 to 1.27$)$ & $<0.0001$ & 1.48 & (1.33 to 1.65$)$ & $<0.0001$ & 1.30 & (1.05 to 1.61$)$ & 0.018 \\
\hline \multicolumn{10}{|l|}{ Model 2 fully adjusted $t$} \\
\hline \multicolumn{10}{|l|}{ Women $n=13577$} \\
\hline Back bend or twisted & 1.02 & (1.00 to 1.04$)$ & 0.095 & 1.24 & (1.17 to 1.32 ) & $<0.0001$ & 1.16 & (1.04 to 1.30$)$ & 0.008 \\
\hline Lifting or carrying & 1.03 & (1.01 to 1.06$)$ & 0.008 & 1.24 & (1.16 to 1.33$)$ & $<0.0001$ & 1.29 & (1.15 to 1.44$)$ & $<0.0001$ \\
\hline Wet hands & 1.01 & (0.99 to 1.04 ) & 0.26 & 1.26 & (1.19 to 1.35$)$ & $<0.0001$ & 1.08 & (0.96 to 1.21$)$ & 0.189 \\
\hline \multicolumn{10}{|l|}{ Men $n=9342$} \\
\hline Back bend or twisted & 1.06 & (1.02 to 1.11$)$ & 0.002 & 1.36 & (1.22 to 1.52$)$ & $<0.0001$ & 1.32 & (1.06 to 1.63$)$ & 0.012 \\
\hline Lifting or carrying & 1.05 & (1.01 to 1.09 ) & 0.016 & 1.47 & (1.32 to 1.64$)$ & $<0.0001$ & 1.60 & (1.30 to 1.96$)$ & $<0.0001$ \\
\hline Wet hands & 1.05 & (1.00 to 1.10$)$ & 0.037 & 1.13 & (0.99 to 1.28$)$ & 0.066 & 1.04 & (0.81 to 1.35$)$ & 0.744 \\
\hline \multicolumn{10}{|c|}{ Psychosocial work environment } \\
\hline \multicolumn{10}{|c|}{ Model 1 partly adjusted ${ }^{*}$} \\
\hline \multicolumn{10}{|l|}{ Women $n=16357$} \\
\hline Poor influence & 1.70 & (1.63 to 1.79$)$ & $<0.0001$ & 1.96 & (1.72 to 2.23 ) & $<0.0001$ & 1.99 & (1.59 to 2.50$)$ & $<0.0001$ \\
\hline Role conflicts & 1.29 & (1.24 to 1.34$)$ & $<0.0001$ & 1.66 & (1.49 to 1.85$)$ & $<0.0001$ & 1.96 & (1.63 to 2.36 ) & $<0.0001$ \\
\hline Bullying $\ddagger$ & 1.33 & (1.30 to 1.37 ) & $<0.0001$ & 1.56 & (1.46 to 1.66$)$ & $<0.0001$ & - & & \\
\hline \multicolumn{10}{|l|}{ Men $n=11322$} \\
\hline Poor influence & 2.12 & (1.98 to 2.26$)$ & $<0.0001$ & 2.47 & (2.03 to 3.01 ) & $<0.0001$ & 1.63 & (1.10 to 2.42 ) & 0.015 \\
\hline Role conflicts & 1.16 & (1.10 to 1.23$)$ & $<0.0001$ & 1.30 & (1.10 to 1.53$)$ & 0.002 & 1.14 & (0.83 to 1.57 ) & 0.417 \\
\hline Bullying $\ddagger$ & 1.36 & (1.30 to 1.41$)$ & $<0.0001$ & 1.63 & (1.46 to 1.82 ) & $<0.0001$ & - & & \\
\hline \multicolumn{10}{|l|}{ Model 2 fully adjusted $t$} \\
\hline \multicolumn{10}{|l|}{ Women $n=13577$} \\
\hline Poor influence & 1.48 & (1.41 to 1.57 ) & $<0.0001$ & 1.41 & (1.21 to 1.63$)$ & $<0.0001$ & 1.49 & (1.15 to 1.92$)$ & 0.002 \\
\hline Role conflicts & 1.17 & (1.12 to 1.22 ) & $<0.0001$ & 1.38 & (1.22 to 1.55$)$ & $<0.0001$ & 1.67 & (1.35 to 2.05 ) & $<0.0001$ \\
\hline Bullying $\ddagger$ & 1.18 & (1.15 to 1.22 ) & $<0.0001$ & 1.31 & (1.21 to 1.42 ) & $<0.0001$ & - & & \\
\hline \multicolumn{10}{|l|}{ Men $\mathrm{n}=9342$} \\
\hline Poor influence & 1.72 & (1.59 to 1.85$)$ & $<0.0001$ & 1.92 & (1.53 to 2.42 ) & $<0.0001$ & 1.32 & (0.84 to 2.08 ) & 0.229 \\
\hline Role conflicts & 1.09 & (1.03 to 1.16$)$ & 0.005 & 1.27 & (1.05 to 1.53$)$ & 0.013 & 1.32 & (0.92 to 1.89 ) & 0.138 \\
\hline Bullying $\ddagger$ & 1.17 & (1.11 to 1.22 ) & $<0.0001$ & 1.29 & (1.13 to 1.47 ) & $<0.001$ & - & & \\
\hline
\end{tabular}

*Adjusted for age, education, private/public sector, and survey round.

†Adjusted as previous model plus additionally adjusted for depression, eczema, back disease, other chronic illness, SA in 2 months up to baseline, smoking, exercise, plus physical work environment factors are adjusted for psychosocial work environment, and psychosocial work environment factors are adjusted for physical work environment.

\#'Bullying' did not fulfil the proportional hazard assumption in analyses with SA episodes $\geq 21$ days and is therefore not shown.

SA are highest if we focus on SA episodes $\geq 6$ days. A recent cohort study found that a reduction in physical workload was non-significantly associated with short-term SA episodes of 1-3 days, but significantly associated with SA of more than 14 days. $^{31}$

The psychosocial work environment factors 'Role conflicts' and 'Bullying' had a trend towards higher HRs with SA episodes $\geq 6$ days compared with SA episodes $\geq 1$ day, but the trends were less pronounced than for the physical work environment factors. 'Poor influence' had similar HRs for SA episodes $\geq 1$ day and $\geq 6$ days. This suggest that the factors determining short-term SA may at least to some extent be influenced by psychosocial work environment. The psychosocial work environment factors may be associated with short-term SA episodes due to psychological distress responses ${ }^{32}$ and with long-term SA episodes, due to for example, depression. ${ }^{33}$

The HRs of the physical work environment factors were in general higher for men than for women. Some previous studies $^{3435}$ has shown higher associations for men, in line with our study, but other studies have shown mixed results, ${ }^{3}{ }^{13}$ or higher associations for women. ${ }^{36}$

The HRs of the psychosocial work environment factors were in general higher for women, but some were significantly higher for men. Previous studies have also shown mixed results. ${ }^{8} 3437$ If there is a sex difference, it may be related to a gender-segregated labour market ${ }^{38}$ with different physical 


\section{Physical work environment factors}

Women: Hazard ratio for sickness absence

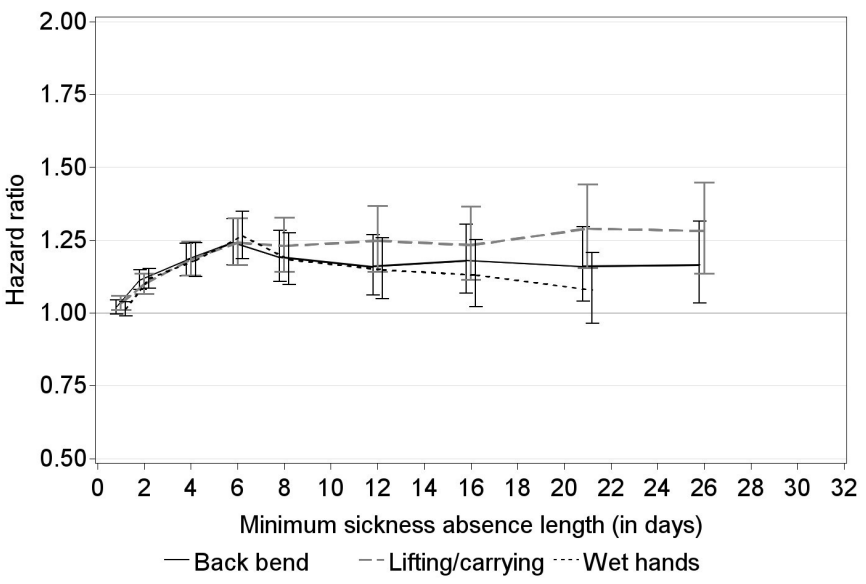

Men: Hazard ratio for sickness absence.

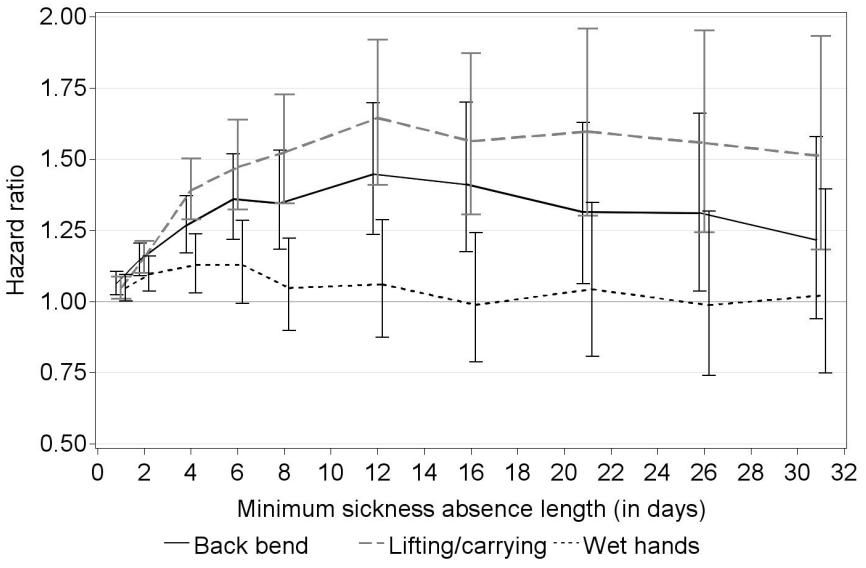

Figure 1 The HRs for different cut-off points for sickness absence (SA) episode length. Analyses of physical work environment adjusted for age, education, private/public sector, survey round, depression, eczema, back disease or other chronic illness, SA in 2 months up to baseline, smoking, exercise and psychosocial work environment. Analyses that did not fulfil the proportional hazard assumption are not shown in the figure.

and psychosocial exposures in male-dominated and femaledominated jobs such as the construction industry compared with cleaning, nursing and childcare. The differences could also be related to different home demands and expectations for men and women.

While our study has notable strengths, e.g. the large sample size and linkage with a national SA register, several limitations must be mentioned. First, the work environment measures were self-reported and the measures may be biased, for example, self-reported physical demands and self-reported wet work are imprecise compared to objective measurements. $^{24} 3940$ Second, the response rate was 50\% and only $63 \%$ of those could be linked to the register, that is, our data are not representative for the entire Danish workforce. Third, our study is an observational study and not a randomised controlled study; hence, it is difficult to show causality. We adjusted our analyses for important covariates, but we may both have adjusted too little or too much. For example, it may be an overadjustment to adjust analyses of 'Wet hands' for eczema, as wet hands may cause or exacerbate occupational hand eczema. ${ }^{22}$ Fourth, while the RoWA include SA of any length, it is possible that companies register SA exceeding 30 days more carefully, since companies can get compensation for salary expense to sick-listed employees, when the SA episodes exceed 30 days. However, a study comparing RoWA with selfreported SA found high correlations, ${ }^{19}$ supporting the validity of RoWA. Fifth, our study is based on data from Denmark and may not be directly transferable to other countries. However, previous comparisons have found that the association between work environment and SA is similar in European countries. ${ }^{41}$

The results of the present study add to the understanding of the association between work environment factors and SA and it may guide researchers when designing SA studies. For example, according to our results, analyses of physical work environment factors should primarily focus on SA episodes $\geq 6$ days. The psychosocial work environment factors 'Role conflict' and 'Bullying' may also have higher associations with SA when focus is on SA episodes $\geq 6$ days; however, for all three psychosocial work factors, the associations were highly

\section{Psychosocial work environment factors}

Women: Hazard ratio for sickness absence.

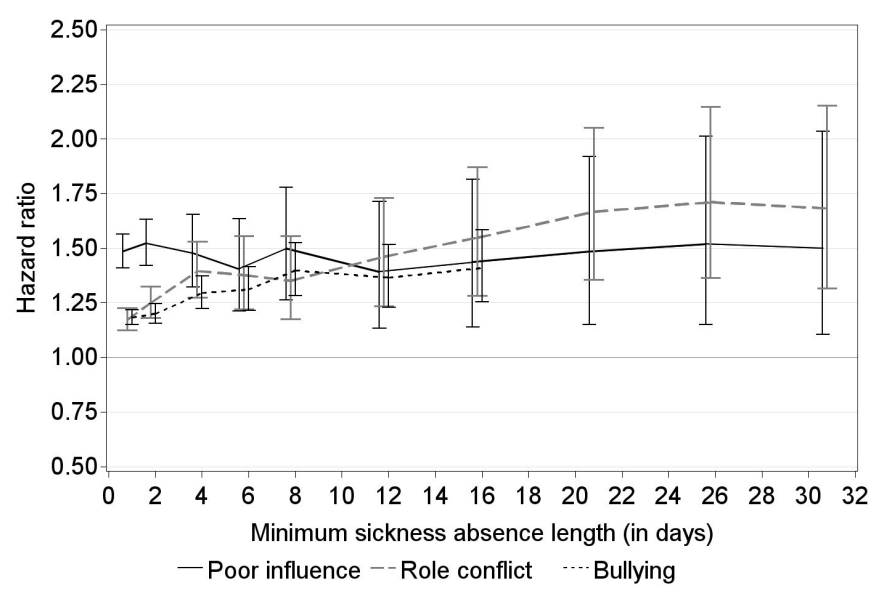

Men: Hazard ratio for sickness absence.

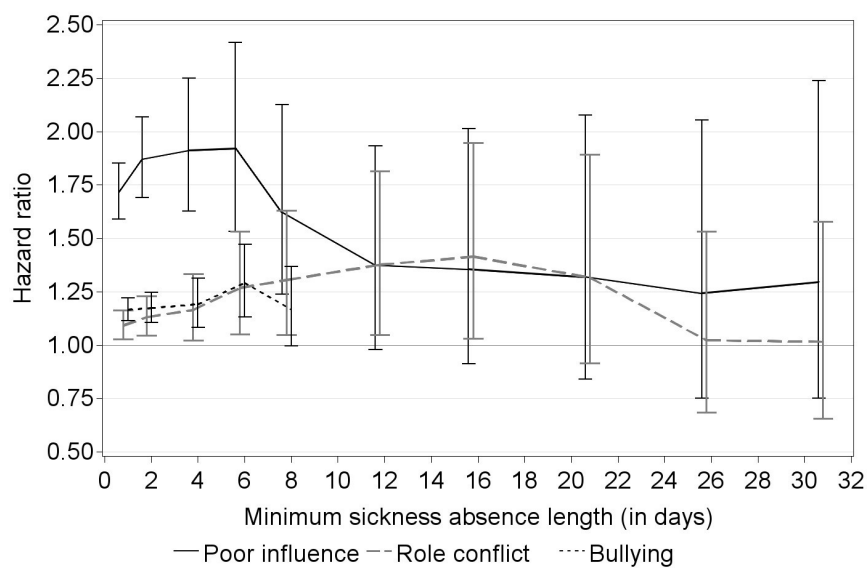

Figure 2 The HRs for different cut-off points for sickness absence (SA) episode length. Analyses for psychosocial work environment adjusted for age, education, private/public sector, survey round, depression, eczema, back disease or other chronic illness, SA in 2 months up to baseline, smoking, exercise and physical work environment. Analyses that did not fulfil the proportional hazard assumption are not shown in the figure. 
significant when all SA episodes were included, that is, analyses of SA episodes $\geq 1$ day.

The practical implications of our study are that reduction of strenuous physical work will probably not reduce short-term SA episodes of less than 5 days, but may reduce longer SA episodes. By contrast, improving certain aspects of the psychosocial work environment may be important in the prevention of SA of all lengths. Thus, improving different aspects of the work environment seem to be important to deal with SA in general.

\section{CONCLUSION}

For both men and women, the physical work environment factors 'Back bend or twisted' and 'Carrying and lifting' had larger and more significant associations with SA if analyses focused on SA episodes $\geq 6$ days. The psychosocial work environment factors had highly significant associations with SA both when short-term SA was included and excluded, though 'Role conflict' and 'Bullying' may have slightly larger associations with SA if analyses focus on SA episodes $\geq 6$ days.

\section{Twitter Lars L Andersen @larslandersen}

Acknowledgements The authors are grateful to the Surveillance group at the Danish National Research Centre for the Working Environment for valuable assistance with access to and quality assurance of data.

Contributors All authors were involved in the design of the study. S.V.Thorsen performed the analyses and drafted the paper. M-A.Flyvholm, J.Pedersen, U.Bültmann, L.L.Andersen and J.B. Bjorner made critical revisions to the draft and helped with the interpretation of the results. All authors approved the final manuscript.

Funding The present study was funded by a special grant the Danish Research Center of the Working Environment receives from the state. The grant is given in accordance with the Danish Finance Act \$17.21.02.30.

Competing interests None declared.

Patient consent for publication Not required.

Ethics approval The Danish Data Protection Agency has approved the WEHD survey (journal number 2012-54-0017). According to Danish law, questionnairebased and register-based studies do not need approval by committees of ethics, nor do they need informed consent. ${ }^{42} 43$

Provenance and peer review Not commissioned; externally peer reviewed.

Data availability statement Data may be obtained from a third party and are not publicly available. Access to sickness absence data can be bought from Statistics Denmark. Access to work environment data can be granted by the Danish National Research Centre for the Working Environment.

Open access This is an open access article distributed in accordance with the Creative Commons Attribution Non Commercial (CC BY-NC 4.0) license, which permits others to distribute, remix, adapt, build upon this work non-commercially, and license their derivative works on different terms, provided the original work is properly cited, appropriate credit is given, any changes made indicated, and the use is non-commercial. See: http://creativecommons.org/licenses/by-nc/4.0/.

\section{ORCID iDs}

Sannie Vester Thorsen http://orcid.org/0000-0002-8778-9053

Mari-Ann Flyvholm http://orcid.org/0000-0002-8942-754X

Jacob Pedersen http://orcid.org/0000-0003-4429-3485

Ute Bültmann http://orcid.org/0000-0001-9589-9220

Lars L Andersen http://orcid.org/0000-0003-2777-8085

Jakob Bue Bjorner http://orcid.org/0000-0001-7033-8224

\section{REFERENCES}

1 Flyvholm M, Thorsen SV, Bültmann U. Fraværsrapport 2019. Deskriptiv analyse af lønmodtagernes sygefravær i Danmark - belyst ud fra register- og spørgeskemadata Fraværsrapport, København: Det Nationale Forskningscenter for Arbejdsmiljø 2019.

2 Beskæftigelsesministeriet. NOTAT - Udviklingen i udgifterne i sygedagpengesystemet, København Beskæftigelsesministeriet 2018;3.

3 Bang Christensen $\mathrm{K}$, Lund T, Labriola M, et al. The fraction of long-term sickness absence attributable to work environmental factors: prospective results from the Danish work environment cohort study. Occup Environ Med 2007;64:487-9.
4 Clausen T, Burr H, Borg V. Do psychosocial job demands and job resources predict long-term sickness absence? an analysis of register-based outcomes using pooled data on 39,408 individuals in four occupational groups. Int Arch Occup Environ Health 2014;87:909-17.

5 Rugulies R, Aust B, Pejtersen JH. Do psychosocial work environment factors measured with scales from the Copenhagen psychosocial questionnaire predict registerbased sickness absence of 3 weeks or more in Denmark? Scand J Public Health 2010:38:42-50.

6 Andrea H, Beurskens AJHM, Metsemakers JFM, et al. Health problems and psychosocial work environment as predictors of long term sickness absence in employees who visited the occupational physician and/or general practitioner in relation to work: a prospective study. Occup Environ Med 2003;60:295-300.

7 Munir F, Burr H, Hansen JV, et al. Do positive psychosocial work factors protect against 2-year incidence of long-term sickness absence among employees with and those without depressive symptoms? A prospective study. J Psychosom Res 2011;70:3-9.

8 Lund T, Labriola M, Christensen KB, et al. Psychosocial work environment exposures as risk factors for long-term sickness absence among Danish employees: results from DWECS/DREAM. J Occup Environ Med 2005;47:1141-7.

9 Nielsen MB, Indregard A-MR, Øverland S. Workplace bullying and sickness absence: a systematic review and meta-analysis of the research literature. Scand I Work Environ Health 2016:42:359-70.

10 Andersen LL, Thorsen SV, Flyvholm M-A, et al. Long-Term sickness absence from combined factors related to physical work demands: prospective cohort study. Eur J Public Health 2018;28:824-9.

11 Lund T, Labriola M, Christensen KB, et al. Physical work environment risk factors for long term sickness absence: prospective findings among a cohort of 5357 employees in Denmark. BMJ 2006;332:449-52.

12 Sterud T. Work-Related mechanical risk factors for long-term sick leave: a prospective study of the general working population in Norway. Eur J Public Health 2014;24:111-6.

13 Alfonso JH, Tynes T, Thyssen JP, et al. Self-Reported occupational skin exposure and risk of Physician-certified long-term sick leave: a prospective study of the general working population of Norway. Acta Derm Venereol 2016;96:336-40.

14 Head J, Kivimäki M, Siegrist J, et al. Effort-reward imbalance and relational injustice at work predict sickness absence: the Whitehall II study. J Psychosom Res 2007:63:433-40.

15 Holtermann A, Hansen JV, Burr H, et al. Prognostic factors for long-term sickness absence among employees with neck-shoulder and low-back pain. Scand J Work Environ Health 2010;36:34-41.

16 Johansen V. Risk factors of long-term sickness absence in Norway and Sweden. Nord J Soc Res 2013:71-82

17 Krane L, Fleten N, Stapelfeldt CM, et al. Comparison of sick leave patterns between Norway and Denmark in the health and care sector: a register study. Scand J Public Health 2013;41:684-91.

18 Thorsen SV, Friborg C, Lundstøm B, et al. Sickness absence in the Nordic countries, Copenhagen 2015

19 Thorsen SV, Flyvholm M-A, Bültmann U. Self-Reported or register-based? A comparison of sickness absence data among 8110 public and private employees in Denmark. Scand J Work Environ Health 2018;44:631-8.

20 Jensen CT, Johnsen NF, Linde P, et al. Danskernes arbejdsmiljø 2016 Danskernes Arbejdsmiljø, København: Det Nationale Forskningcenter for Arbejdsmiljø (NFA) 2018:400.

21 Denmark S. Documentation of statistics for absence 2017. 21. Copenhagen: Statistics Denmark, 2019.

22 Lund T, Petersen SB, Flachs EM, et al. Risk of work-related hand eczema in relation to wet work exposure. Scand I Work Environ Health 2020;46:437-45.

23 Rugulies R, Madsen IEH, Hjarsbech PU, et al. Bullying at work and onset of a major depressive episode among Danish female eldercare workers. Scand J Work Environ Health 2012:38:218-27.

24 Flyvholm M-A, Lindberg M, OEESC-2005 organizing committee. OEESC2005--summing up on the theme irritants and wet work. Contact Dermatitis 2006:55:317-21.

25 Madsen IEH, Gupta N, Budtz-Jørgensen E, et al. Physical work demands and psychosocial working conditions as predictors of musculoskeletal pain: a cohort study comparing self-reported and job exposure matrix measurements. Occup Environ Med 2018;75:752-8.

26 Christensen KB, Andersen PK, Smith-Hansen L, et al. Analyzing sickness absence with statistical models for survival data. Scand J Work Environ Health 2007;33:233-9.

27 Sun RJ. Paper 255-2010: analysis of survival data with recurrent events using SAS. SAS Global Forum Proceedings 2010.

28 Kukhareva P. Paper 428-2013: COX proportional hazard model evaluation in one shot. SAS Global Forum Proceedings 2013.

29 Tibshirani G. An introduction to statistical learning. New York: Springer Science+Business Media, 2013.

30 Coenen P, Gouttebarge V, van der Burght ASAM, et al. The effect of lifting during work on low back pain: a health impact assessment based on a meta-analysis. Occup Environ Med 2014;71:871-7. 
31 Shiri R, Hiilamo A, Pietilainen O, et al. Favourable changes in physical working conditions and the risk of all-cause sickness absence: a pseudo-experiment. Eur $J$ Public Health 2019.

32 Volmer J, Fritsche A. Daily negative work events and employees' physiological and psychological reactions. Front Psychol 2016;7:7.

33 Rugulies R, Bültmann U, Aust B, et al. Psychosocial work environment and incidence of severe depressive symptoms: prospective findings from a 5-year follow-up of the Danish work environment cohort study. Am J Epidemiol 2006;163:877-87.

34 Foss L, Gravseth HM, Kristensen P, et al. The impact of workplace risk factors on longterm musculoskeletal sickness absence: a registry-based 5-year follow-up from the Oslo health study. J Occup Environ Med 2011;53:1478-82.

35 Lund T, Labriola M, Christensen KB, et al. Return to work among sickness-absent Danish employees: prospective results from the Danish work environment cohort Study/National register on social transfer payments. Int J Rehabil Res 2006:29:229-35.

36 Corbett K, Gran JM, Kristensen P, et al. Adult social position and sick leave: the mediating effect of physical workload. Scand J Work Environ Health 2015;41:542-53.
37 Nielsen ML, Rugulies R, Christensen KB, et al. Psychosocial work environment predictors of short and long spells of registered sickness absence during a 2-year follow up. J Occup Environ Med 2006;48:591-8.

38 Gonäs L, Wikman A, Vaez M, et al. Changes in the gender segregation of occupations in Sweden between 2003 and 2011. Scand J Public Health 2019;47:344-7.

39 Gupta N, Heiden M, Mathiassen SE, et al. Prediction of objectively measured physical activity and sedentariness among blue-collar workers using survey questionnaires. Scand J Work Environ Health 2016:42:237-45.

40 Gupta N, Heiden M, Mathiassen SE, et al. Is self-reported time spent sedentary and in physical activity differentially biased by age, gender, body mass index, and low-back pain? Scand J Work Environ Health 2018:44:163-70.

41 Slany C, Schütte S, Chastang J-F, et al. Psychosocial work factors and long sickness absence in Europe. Int J Occup Environ Health 2014;20:16-25.

42 Ethics TCoBR. Committee system on biomedical research ethics. guidelines about notification, 2011. Available: http://www. dnvk. dk

43 Agency TDDP. Private research and statistics projects, 2010. Available: https://www. datatilsynet. dk 